\title{
Selection Between One-Time Transfer and University-Industry Cooperation in Technology Transfer: A Matching Model
}

\author{
Longtian Zhang, Hong $\mathrm{Li}^{*}$ \\ Email address: \\ plong511@pku.edu.cn (Longtian Zhang), lihong@ucas.ac.cn (Hong Li) \\ ${ }^{*}$ Corresponding author
}

School of Economics and Management, University of Chinese Academy of Sciences, Beijing, China

\section{To cite this article:}

Longtian Zhang, Hong Li. Selection Between One-Time Transfer and University-Industry Cooperation in Technology Transfer: A Matching Model. International Journal of Economics, Finance and Management Sciences. Vol. 5, No. 5, 2017, pp. 235-245.

doi: $10.11648 /$ j.ijefm.20170505.12

Received: August 4, 2017; Accepted: September 6, 2017; Published: September 14, 2017

\begin{abstract}
Although the process of technology transfer including university-industry cooperation and other forms has been widely investigated in previous literature, it still lacks a comprehensive modeling of this process. This paper presents a model describing the selection between one-time transfer, which is usually known as patenting and licensing, and university-industry cooperation in the situation of perfect information, and find out that the bargaining power of both sides, along with the periods that the underlying technologies can be profitable are important factors that may influence the decisions of the trade forms and the corresponding fees, respectively. The simulating results show that, given the profitable period of the underlying technologies is long enough, as the bargaining power of scientists become stronger, the selection of form of trade undergoes a changing pattern of from one-time transfer to cooperation. Moreover, to deal with conflicts that the both sides may face in some cases, two rules that are proposed under the situation of with and without intermediaries are discussed respectively, and we find that the allocation under the two rules are the same. This conclusion helps providing theoretical support for introducing technology intermediaries into the process of technology transfer.
\end{abstract}

Keywords: Matching Model, Technology Transfer, University-Industry Cooperation

\section{Introduction}

In recent decades, the role of universities and other institutions is increasingly expanding beyond their traditional tasks of teaching and researching to promote innovation performance and economic growth in neighboring regions mainly through knowledge spillovers, which are usually in the form of technology transfer (TT) [1,2]. Literature studying on this kind of topics can generally be divided into two aspects. On one hand, based on the endogenous growth theory, knowledge spillover theory of entrepreneurship (KSTE) tries to expand the microeconomic foundation by identifying and adding some factors of knowledge spillover into the original model to describe their behaviors and performances on affecting economic growth of a region or a country [3-6]. On the other hand, some other studies focus on the relationships between universities and firms in the process of technology transfer, e.g., how to improve the "Industry-Science Links" and remove the obstacles among them [7-9], and how to select appropriate modes of cooperation for different kinds of scientists under different kinds of situations [2, 10]. While there are large sums of studies on the former kinds of topics, the latter ones have not been fully investigated yet, and to the best of our own knowledges, lack an integrated model to describe the different characters and jointly behaviors of the agents in different forms of TT. Therefore, the incentives and the mechanisms at the core of selecting different kinds of cooperating forms between universities and firms are worth studying, and this can give some advice on shaping the policies of TT to make it more beneficial to both of the two sides and the whole society.

Perkmann etc. [11] classify the relationship between academic engagement and commercialization into two categories: TT which represents collaboration and 
commercialization occurred via academic entrepreneurship, and patenting or licensing contracts, which can be viewed as a preliminary state of cooperation. Both academic engagement and commercialization are driven independently and tend to be pursued in different goals. While some researchers are focusing on their own research and do not care about the commercial values of their academic outputs, entrepreneurs and some entrepreneur-type researchers are working on common projects that may be commercially valuable.

Some researchers have studied the driving forces and obstacles of university-industry (U-I) cooperation. Leyden and Link [12] set up an endogenous growth model relating to KSTE, and show that universities have to structure their programs to become more cost-efficient so that they can be attractive to be a complement of private sector of $R \& D$ activities. Lehmann and Menter [13] collect panel data set from 1998 to 2012 in Germany and find that universities and regional wealth interact with each other mutually, which supports the idea that university and regional endowment are linked together. Calcagnini etc. [2] find that human capitals such as graduates can significantly influence the location decisions of start-ups, i.e., firms are usually set closed to universities. Weng and Chang [14] view organizational heterogeneity as a key factor that influences the effects of U-I cooperation policy in higher education institutions. They study the data of Taiwan and find the positive relationship between those kinds of heterogeneity in graduate institutes and their performances.

While U-I cooperation has been studied quite deeply, there is not too much literature on the preliminary form of TT, i.e., patenting and licensing. Studies usually focus on identifying the characteristics of the scientists who needs this form of technology transfer, but seldom analyze the mechanism of this kind of selection. Link and Welsh [15] study the characteristics of young inventors and their relationships with the propensity to form new business. Würmseher [10] divides scientists into three types based on their attitudes towards commercialization, and the second type of scientists in his paper, who have very strong focus on academic targets and no ambitious to engage in venturing projects, need to match with surrogate entrepreneurs, who will get all rights of the inventions. In this paper, some driving forces can be identified that make the process of technology transfer to be in the form of patenting and licensing in some situations rather than U-I cooperation which can be widely seen in many studies.

This paper is based on the researches and conclusions of the above researchers. For further conclusions, a matching model is set up to integrate the two forms of TT into the same system and describe the changing patterns of the selecting behavior of both the scientists' and the entrepreneurs' sides. Matching models are originally proposed to study the matching problems on labor markets [16-18]. When two groups of people meet each other in a market to bargain for something, and after this process they form some kinds of bonds in a certain probability to make profits together, there arises problems of matching and allocating the underlying outputs. This kind of process can also be set in the situation of scientists searching for cooperation with entrepreneurs. Similar researches have been done by Calcagnini etc. [8], but this paper is just based on the situation of cooperating, so this paper is extended from this.

In particular, this paper is set to discuss the following questions: what are the incentives and obstacles for scientists and entrepreneurs to select patenting or licensing, which is called one-time transfer in this paper, or cooperation in a certain situation, respectively? How will be the bargaining process be set when the two sides have conflicts on the selection of transaction forms? Which kind of allocations will be more desirable? What factors may influence the results of the allocations? To answer these questions, a theoretical model of matching between university scientists and industrial entrepreneurs is presented, first in the basic situation of just selecting one-time transfer as the unique form and then combine with the form of cooperation to construct a selecting-and-then-matching model. Besides, some simulations are done to study the relationships between some important factors and the final allocations of the bargaining process.

The paper is organized as follows. In Section 2, the basic model is set up under the situation of one-time transfer as a unique form, then solve it and do some discussions. In Section 3 , the integrated model is proposed and selection behaviors of the both sides are described separately. In Section 4, the bargaining process is modeled and the simulation results are presented. And finally, Section 5 concludes and compares the different allocations derived from different rules.

\section{The Basic Model}

The model is based on a simple situation of complete information, which means the two sides of the transaction, scientists and entrepreneurs, both can understand the invention and know clearly the returns from it in the future. This assumption rules out the situation that one of the transaction sides cannot estimate the future returns from the technology, or have incorrect estimation of them, which may lead to some distortions to the allocation and other influential factors besides those being discussed in this paper.

The basic model is just the situation that both sides can only select one-time transfer as the unique form of transaction, which is a special case of cooperation, for it can be viewed as a kind of cooperation that will break with certainty in the next period. This model is closely connected to the models presented in Trejos and Wright [19] and Pissarides [16].

\subsection{Settings}

The economy consists two kinds of people, scientists and entrepreneurs. Scientists can gain some technologies every period randomly, but they do not have the ability to change the technologies into profits and their own utilities directly. Meanwhile, entrepreneurs do not have the ability to gain technologies, but they can change them into profits, so they have to buy technologies from scientists. Every period, both sides meet each other randomly in the market and bargain for 
the price of the technologies. Once the transaction is established, they both can be benefited.

Every period, there are $N$ scientists who either have technologies to sell $(s)$ or have nothing in hand $(n)$. The total number of scientists is $N=n+s$, which is a given, fixed number for all periods. There are $v$ entrepreneurs in the economy to offer sales to scientists. We assume that all transactions are only between one entrepreneur and one scientist.

Initially, there is no scientist who has technologies. At the beginning of period 1 , every scientist can have the probability of $\theta(0 \leq \theta \leq 1)$ to get a technology. Then, they go to the market to meet with entrepreneurs and sell the technologies. Assume that every period, the number of people who can successfully make the transaction is:

$$
T=M_{0} v^{\alpha} S^{\beta}
$$

where $M_{0}, \alpha$ and $\beta$ are some policy parameters, and this is called matching function. Meanwhile, we assume that the values of these parameters are set to satisfy $T \leq \min \{v, s\}$. The matching function is in the form of a Cobb-Douglas function, where $\alpha$ and $\beta$ determines the return of the matching process. For simplicity, just the case of constant returns to scale is focused on where $\alpha+\beta=1$. Thus, the matching function can be further written as

$$
T=M_{0} s^{1-\alpha} v^{\alpha}
$$

Let $m(x)$ be the probability that a scientist can find an appropriate entrepreneur to sell his technology, that is:

$$
m(x)=\frac{M_{0} s^{1-\alpha} v^{\alpha}}{s}=M_{0}\left(\frac{v}{s}\right)^{\alpha}=M_{0} x^{\alpha}
$$

where $x=v / s$ is the ratio of the number of entrepreneurs to the number of scientists who have technologies to be sold. Similarly, let $q(x)$ be the probability that an entrepreneur can find an appropriate scientist to buy technology from, that is:

$$
q(x)=\frac{M_{0} s^{1-\alpha} v^{\alpha}}{v}=M_{0} x^{\alpha-1}=\frac{m(x)}{x}
$$

Both probabilities are related to $x$, which can be viewed as the tightness of the TT market, i.e., the difficulty that a scientist can meet an entrepreneur in the market.

Besides, we assume that scientists are risk-averse, that is, their utility functions $u(w)$ have the following properties: $u^{\prime}(w)>0$ and $u^{\prime \prime}(w)<0$. We also assume that entrepreneurs are at least not risk-averse, that is, their utility functions $i(w)$ have the following properties: $i^{\prime}(w)>0$ and $i^{\prime \prime}(w) \geq 0$.

It is noteworthy that the ratio of $s$ to the total number of scientists $N$ will converge to a certain fixed number after some periods have passed, and the corresponding proof is provided in Appendix. So, we denote $\theta_{1}$ as the steady-state ratio of $s$ to $N$ This is an important property, and it will help us make the solution of the model simpler and more meaningful.

\subsection{Value Functions of the Two Sides}

The behavior of the two sides can be described in the form of their value functions. Let $V^{i, e}, V^{i, u}$ and $V^{u}$ denote the value of scientists who have technologies and successfully sell them, who have technologies but fail to sell them, and who have no technologies, respectively. For the first kind of scientists who have technologies and sell them, they gain utilities from the selling and then become having nothing in hand. In the next period, there are three possible states of them: gain technologies again and sell them, gain technologies again but fail to sell them, and remain having nothing in hand. The possibility of these three states are $\theta_{1} m(x),\left(1-\theta_{1}\right)$ and $\theta_{1}(1-m(x))$, respectively. Thus, their value functions can be described by using the Bellman equations as the following:

$$
\begin{gathered}
V_{t}^{i, e}=u(w)+\beta\left[\theta_{1} m(x) V_{t+1}^{i, e}+\left(1-\theta_{1}\right) V_{t+1}^{u}+\right. \\
\left.\theta_{1}(1-m(x)) V_{t+1}^{i, u}\right]
\end{gathered}
$$

where $w$ is the price of the underlying technologies, and $\beta$ is the discount factor. In the steady-state, the value functions of every period will converge, so the subscript of periods can be dropped out. Then, Eq. (5) becomes:

$$
\begin{aligned}
V^{i, e}=u(w)+ & \beta\left[\theta_{1} m(x) V^{i, e}+\left(1-\theta_{1}\right) V^{u}+\theta_{1}(1-\right. \\
& \left.m(x)) V^{i, u}\right]
\end{aligned}
$$

Similarly, for the second kind of scientists who have technologies but fail to sell them, they gain nothing but still have the technologies in hand. In the next period, they go on searching for entrepreneurs to sell their technologies, so there are two possible states in this case: sell the technologies successfully, and fail to sell again. The possibility of these two states are $m(x)$ and $(1-m(x))$. Thus, in the steady-state, their value functions can be described as the following:

$$
V^{i, u}=\beta\left[m(x) V^{i, e}+(1-m(x)) V^{i, u}\right]
$$

Finally, the value functions of those scientists who have no technologies in hand can also be derived. They gain nothing, and for the next period, their states are similar to those scientists who have just sold their technologies. Therefore,

$V^{u}=\beta\left[\theta_{1} m(x) V^{i, e}+\left(1-\theta_{1}\right) V^{u}+\theta_{1}(1-m(x)) V^{i, u}\right]$

The value functions of entrepreneurs' side can also be derived under similar process. Let $J^{e}$ and $J^{u}$ denote the value functions of entrepreneurs who have and have not bought technologies from scientists this period, respectively. For the first kind who have bought technologies, they pay the price of the underlying technologies and can have all of the returns from them in the future. In the next period, they go on searching and bargaining with scientists to buy new technologies, and will have two different states: succeed in trading with probability of $q(x)$, and fail with probability of $(1-q(x))$. Thus, their value functions can be described as the following:

$$
J^{e}=i(R-w)+\beta\left[q(x) J^{e}+(1-q(x)) J^{u}\right]
$$

where $R$ is the present value of all the returns from the technologies in the future.

Similarly, for the second kind of entrepreneurs who fail to 
buy technologies from scientists, they can get nothing. In the next period, they go on searching, so their possible states will be the same as those who succeed in buying inventions in the last period. Thus, the value functions can be derived as the following:

$$
J^{u}=\beta\left[q(x) J^{e}+(1-q(x)) J^{u}\right]
$$

\subsection{Price Determination and Discussions}

Now that the value functions of all kinds of scientists and entrepreneurs have been derived, when given certain appropriate value of the parameters and the price of one-time transfer, the allocations of the bargaining process can be derived. As has been proved in Trejos and Wright [19], the sequential game of bargaining is equivalent to a Nash bargaining process, therefore, the allocations can simply be derived in the form of a maximization problem related to the bargaining power of both sides. Formally, the price of the inventions is determined by:

$$
w=\operatorname{argmax}_{w}\left(V^{i, e}-V^{i, u}\right)^{\phi}\left(J^{e}-J^{u}\right)^{1-\phi}
$$

where $\phi$ is the bargaining power of scientists. This parameter is ranged from 0 to 1 , when it is closed to 0 , entrepreneurs have larger power on determining the results of bargaining, and in a relatively powerful statue; when it is closed to 1 , scientists are more powerful. It is an exogeneous variable which can be determined by the structure of the society, the attitude of the government towards technology transfer, the ability of scientists in negotiating with entrepreneurs, etc. Besides, $\left(V^{i, e}-V^{i, u}\right)$ stands for the excess values of scientists, which means the net benefits scientists can get if they choose to sell their technologies but not leave the technologies in hand for the next period. Similarly, $\left(J^{e}-J^{u}\right)$ is the excess value of entrepreneurs. In addition, considering the incentives of participating in the trade of the two sides, the participation constraint should be satisfied:

$$
\begin{gathered}
V^{i, e} \geq V^{i, u} \geq V^{u} \\
J^{e}-J^{u} \geq 0
\end{gathered}
$$

which means trading is at least better than not trading, and having inventions is at least better than not having any inventions.

In order to get the explicit expression of price, Eq. (11) can first be transformed into logarithmic form and $w$ can be derived from the first order condition

$$
\phi \frac{\frac{\partial\left(V^{i, e}-V^{i, u}\right)}{\partial w}}{V^{i, e}-V^{i, u}}+(1-\phi) \frac{\frac{\partial\left(J^{e}-J^{u}\right)}{\partial w}}{J^{e}-J^{u}}=0
$$

From Eq. (6) (8), they can be solved to derive the value functions of scientists:

$$
V^{i, e}-V^{i, u}=u(w) \frac{(1-\beta)\left(1-\beta\left(1-\theta_{1}\right)\right)}{(1-\beta(1-m(x)))\left(1-\beta\left(1-\theta_{1}\right)\right)-\theta_{1} \beta m(x)} \equiv
$$

where $A$ is a constant determined by the parameters of the model. Then, value functions of entrepreneurs can be derived from Eq. (9) (10):

$$
J^{e}-J^{u}=i(R-w)
$$

Substitute Eq. (15) and (16) into Eq. (14), it can have:

$$
\phi \frac{u^{\prime}(w)}{u(w)}-(1-\phi) \frac{i^{\prime}(R-w)}{i(R-w)}=0
$$

and the relationships between the price $w$ and all kinds of parameters can be derived.

From Eq. (17), applying the implicit function theorem, it can be shown that when

$$
i^{\prime \prime}(R-w) i(R-w)<\left(i^{\prime}(R-w)\right)^{2}
$$

is satisfied, we have $\partial w / \partial \phi>0$. If the utility function is set in a form of polynomial of degree $a$, i.e., for simplicity, the functional form is set as $i(x)=x^{a}$, where $a$ is a parameter that determines the degree, Inequation (18) reduces to

$$
a(a-1) x^{a-2} x^{a}<\left(a x^{a-1}\right)^{2}
$$

and it can be derived that $a>0$, which is always true because we assume $i^{\prime}(x)>0$ here. As a result, in most of the cases, it can be expected that the payoff that scientists can get from the underlying technologies increases when their bargaining power increases. This is a fundamental conclusion which guarantees the validity of the following analysis which extend the model into selection of two forms of trade.

\section{Extension: Selections Between One-Time Transfer and Cooperation}

As has been discussed above, in the real world, besides bargaining for the price of the technologies, scientists and entrepreneurs should also decide the form of the trade, that is, one-time transfer through patenting or licensing, or the two sides establish a kind of cooperating relationship which they will share the returns from the underlying technologies and take the risk together. To model this kind of bargaining process, it is convenient to separate the bargaining process into two stages: first the two sides meet each other in the market and decide which kind of form to trade, then under the condition of the given form of trade, they bargain on the fee respectively. This kind of two-stage selecting and bargaining process has been modeled and discussed in Neal [20] under the situation of career selecting and matching, which describes the process that young men first face the selection of different kinds of jobs, and then bargain with the employers on their wages. The model is based on that research and extend further to make it more suitable for the situation being discussed.

\subsection{Settings}

The settings presented in Section 2.1 are still available here. In addition, some more assumptions on the case of cooperation are added. Suppose that when scientists are in a cooperating relationship with entrepreneurs, they will no 
longer take part in researching activities, that is, they will no longer have the chance to gain new technologies in the future unless the cooperating relationship is broken up. Once this kind of thing happens, the scientists will come back to the researching team to go on their researches, and the previous technologies will be viewed as no longer exist or will no longer produce any returns to either scientists or entrepreneurs. These assumptions are reasonable because in reality, some newly developed technologies may be proved to be not as useful or profitable as they are expected after they are put on the market for a certain period, and the cooperation between scientists and entrepreneurs may undergo some shocks that make it break up.

Formally, we suppose the probability that the cooperating relationship breaks up is denoted as $\delta$ $(0 \leq \delta \leq 1)$, which is an endogenous parameter depended on the period of benefit of the underlying technologies, and this will be discussed in Section 3.2.2. Note that in the case of one-time transfer, it is just a special case of cooperation, i.e., one-time technology transfer is a kind of cooperation that will certainly break up in the next period. When scientists sell their technologies, they will change into the lowest value state of having nothing in hand, but in the next period, they can randomly gain new technologies with probability $\theta$ and change into the high value state. Instead, if they cooperate with entrepreneurs, the probability of remaining in a relatively high value state in the next period is $(1-\delta)$. Therefore, to make it beneficial for scientists to choose the form of cooperating instead of the form of one-time transfer, it is reasonable to suppose that the probability of remaining in the state of cooperation relationship, $(1-\delta)$, should be much larger than the probability of scientists gaining new technologies, $\theta$, which is usually true in the real world.

Finally, we suppose the bargaining process in the model is described in the following: when scientists and entrepreneurs meet each other randomly in the market, they first decide which form of trade they are going to take, and this is determined under several rules which remain to be discussed. After the form of trade is determined, they bargain on the fee. If they decide to trade in the form of one-time transfer, they bargain on the price of the underlying technologies. Otherwise, if they decide to cooperate, they bargain on the ratio of the returns from the underlying technologies that each side can get every period in the future.

Besides, it is noteworthy that in the case of cooperation, the ratio of $s$ to the total number of scientists $N$ will also converge to a certain fixed number after some periods have passed, but this ratio is different from that in the case of one-time transfer. The proof is also provided in Appendix. So, we denote $\theta_{2}$ as the steady-state ratio of $s$ to $N$ in the case of cooperation. In addition, the probability of scientists meet entrepreneurs $m(x)$ and the probability of entrepreneurs meet scientists $q(x)$ will also become different in the case of cooperation. Thus, we denote them as $m\left(x^{\prime}\right)$ and $q\left(x^{\prime}\right)$ respectively in this case to make distinctions with the case of one-time transfer.

\subsection{Value Functions of the Two Sides}

\subsubsection{Value Functions of Scientists}

The behavior of the two sides can also be described in the form of value functions. There are four kinds of scientists in the model: those who have technologies and choose one-time transfer, those who have technologies and choose cooperation, those who have technologies but fail to make any deals, and those who have no technologies in hand. Let $V^{i, t r}, V^{i, c o}, V^{i, u}$ and $V^{u}$ denote the values of scientists of the four kinds, respectively.

For the first kind of scientists who have technologies and choose one-time transfer, similar to the situation in Section 2.2, they gain utilities from the price sold. For the next period, they will face a selection of the two forms of trade. For each of the forms, they will have three states: have technologies and the deal is made, have technologies but fail to make the deal, and have no technologies. They choose the one that will give them higher value, thus the value function is provided in Eq. (20)

$$
\begin{aligned}
& V^{i, t r}= \\
& u(w)+ \\
& \beta \max \left\{\begin{array}{c}
\theta_{1} m(x) V^{i, t r}+\left(1-\theta_{1}\right) V^{u}+\theta_{1}(1-m(x)) V^{i, u}, \\
\theta_{2} m\left(x^{\prime}\right) V^{i, c o}+\left(1-\theta_{2}\right) V^{u}+\theta_{2}\left(1-m\left(x^{\prime}\right)\right) V^{i, u}
\end{array}\right\}
\end{aligned}
$$

For the second kind of scientists who have technologies and choose cooperation, they gain utilities from the proportion they can get from the returns of the underlying technologies. For the next period, they can be still in the relationships of cooperation with probability $(1-\delta)$. Meanwhile, the cooperation may break up with probability $\delta$. In this case, they return to the research team just like those who have sold their technologies to entrepreneurs. Thus, they will face the selection of the two forms of trade, each with three states. In all, the value function is shown in Eq. (21)

$$
\begin{array}{r}
V^{i, c o}= \\
u(c R)+ \\
\beta\left\{(1-\delta) V^{i, c o}+\right. \\
\delta \max \left\{\begin{array}{c}
\theta_{1} m(x) V^{i, t r}+\left(1-\theta_{1}\right) V^{u}+\theta_{1}(1-m(x)) V^{i, u}, \\
\left.\left.\theta_{2} m\left(x^{\prime}\right) V^{i, c o}+\left(1-\theta_{2}\right) V^{u}+\theta_{2}\left(1-m\left(x^{\prime}\right)\right) V^{i, u}\right\}\right\}(21)
\end{array}\right.
\end{array}
$$

where $c$ is the proportion that scientists can get from the returns of the underlying technologies every period. Note that Eq. (20) can be just viewed as a special case of Eq. (21), with $\delta$ equals 1 .

For the third kind of scientists who have technologies but fail to make any deal with entrepreneurs, they will go on searching for entrepreneurs and bargaining with them in the next period. Similarly, they will also face the selection between the two forms of trade, and will choose the higher value one. Thus, the value function of this kind is shown in Eq. (22)

$$
V^{i, u}=\beta \max \left\{\begin{array}{c}
m(x) V^{i, t r}+(1-m(x)) V^{i, u}, \\
m\left(x^{\prime}\right) V^{i, c o}+\left(1-m\left(x^{\prime}\right)\right) V^{i, u}
\end{array}\right\}
$$

Finally, for the last kind of scientists who have no 
technologies in hand, they gain nothing and remain staying in the research team. For the next period, they will face the selections and states the same as those scientists who have sold their technologies or those whose cooperating relationships have broken up. Thus, the value function is provided as Eq. (23)

$V^{u}=\beta \max \left\{\begin{array}{c}\theta_{1} m(x) V^{i, t r}+\left(1-\theta_{1}\right) V^{u}+\theta_{1}(1-m(x)) V^{i, u}, \\ \theta_{2} m\left(x^{\prime}\right) V^{i, c o}+\left(1-\theta_{2}\right) V^{u}+\theta_{2}\left(1-m\left(x^{\prime}\right)\right) V^{i, u}\end{array}\right\}$

These four value functions can be determined by solving Eq. (20) (23). Unlike those in Section 2.3, the equation set is quite complex and difficult to get the explicit solutions. To make the system more visible, some appropriate values of the exogeneous parameters ${ }^{1}$ are chosen and the solutions of the value functions are shown in the form of figures. For the convenience of comparison, the figure is shown together with the value functions of entrepreneurs in Section 3.2.2. It can be seen that in most of the situations, scientists are inclined to select cooperation while in certain situations, selecting one-time transfer is more desirable.

\subsubsection{Value Functions of Entrepreneurs}

There are three kinds of entrepreneurs in the model: those who choose one-time transfer, those who choose cooperation, and those who fail to make deals with scientists. Let $J^{t r}, J^{c o}$ and $J^{u}$ denote the values of entrepreneurs of the three kinds, respectively.

For the first kind of entrepreneurs who choose one-time transfer, they pay the price of the technologies to scientist and can have all of the returns from the underlying technologies in the future. To express all of the returns from the technologies, the periods that the technologies can make profit should be considered. Suppose the underlying technologies can remain profitable for $T$ periods and for each period, its return is $R$, or it can be viewed as that the contracts of patenting and licensing are signed only for $T$ periods. Therefore, the present value of the technologies is given as the following:

$$
\lambda_{T} R=\frac{1-\beta^{T}}{1-\beta} R
$$

where $\lambda_{T}$ is discount factor of the underlying technologies. After the period of benefit $T$ is determined, the probability $\delta$ that a cooperation breaks up can be derived. To make the two forms of trade equivalent, the mean-preserving spread assumption in Stiglitz and Weiss [21] is applied, that is, they should have the same expected returns. Considering that the returns of every period are fixed in this model, $T$ should equal the expected period that a cooperation breaks up. Formally, there is the following expression:

$$
T=\mathbb{E}(t)=\sum_{n=1}^{\infty} n \mathbb{P}(t=n)=\sum_{n=1}^{\infty} n(1-\delta)^{n-1} \delta=\frac{1}{\delta}
$$

To present the changing patterns of selecting behavior, one to four periods is considered in this paper. If the underlying technologies can only profit for one period, in the next period, the entrepreneurs will again search in the market and face two forms of trade, one-time transfer and cooperation. Considering this, the value function is shown in Eq. (26)

$$
J^{t r}=i\left(-w+\lambda_{1} R\right)+\beta \max \left\{\begin{array}{c}
q(x) J^{t r}+(1-q(x)) J^{u}, \\
q\left(x^{\prime}\right) J^{c o}+\left(1-q\left(x^{\prime}\right)\right) J^{u}
\end{array}\right\}
$$

However, if the underlying technologies can profit for more than one period, we suppose that the entrepreneurs will not search in the market until the underlying technologies have expired their profitable period. For instance, if $T=2$, entrepreneurs will be in a state the same as having nothing in hand after they have purchased technologies from scientists in the last period. Then in the next period, they will face the same situations as those provided in Eq. (26). Thus,

$$
J^{t r}=i\left(-w+\lambda_{2} R\right)+\beta J^{u}
$$

Moreover, if $T=3$, let $J^{u s}$ denote the value of entrepreneurs who have purchased technologies from scientists in the last period, and will stay in a state of no searching until the next period. Therefore, Eq. (28) and Eq. (28) can be derived

$$
\begin{gathered}
J^{t r}=i\left(-w+\lambda_{3} R\right)+\beta J^{u s} \\
J^{u s}=\beta J^{u}
\end{gathered}
$$

Value functions of longer profitable period can also be derived in the same way. In this research, only the results of one to four periods are provided, and the results of longer ones are quite similar.

For the second kind of entrepreneurs who choose cooperating with scientists, they have to share the returns from the technologies with scientists and get the remaining part. For the next period, they may remain in the relationships of cooperation, or the relationships break up. Thus, the value function can be written as Eq. (30):

$$
\begin{array}{r}
J^{c o}= \\
i((1-c) R)+ \\
\beta\left\{(1-\delta) J^{c o}+\delta \max \left\{\begin{array}{c}
q(x) J^{t r}+(1-q(x)) J^{u}, \\
q\left(x^{\prime}\right) J^{c o}+\left(1-q\left(x^{\prime}\right)\right) J^{u}
\end{array}\right\}\right\} \quad \text { (30) }
\end{array}
$$

Note that in this case, entrepreneurs will only pay no more than the returns from the technologies in this period, but in the above case, entrepreneurs may pay more than the returns of one period.

Finally, for the last kind of entrepreneurs who fail to trade with scientists, they get nothing. For the next period, they will go on searching for inventions to invest, thus the states they will face are the same as above:

$$
J^{u}=\beta \max \left\{\begin{array}{c}
q(x) J^{t r}+(1-q(x)) J^{u} \\
q\left(x^{\prime}\right) J^{c o}+\left(1-q\left(x^{\prime}\right)\right) J^{u}
\end{array}\right\}
$$




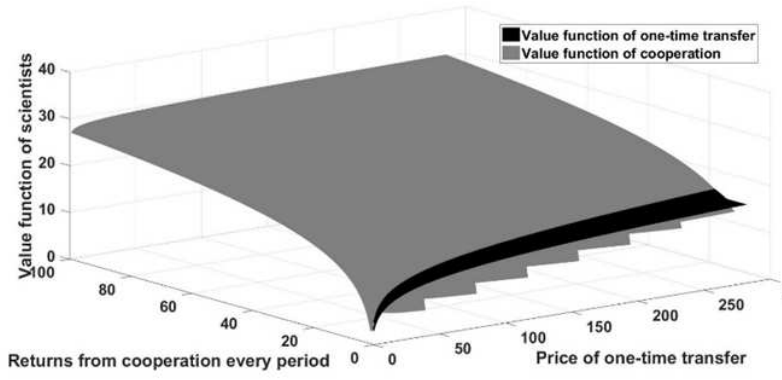

(a) Value functions of scientists

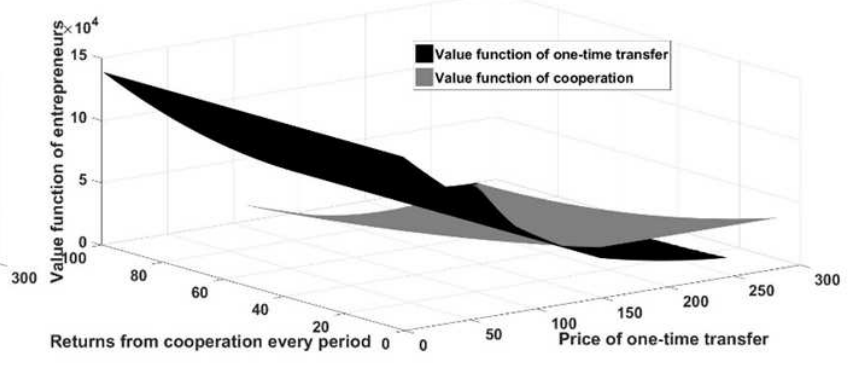

(b) Value functions of entrepreneurs

Figure 1. Value functions of the two sides when $T=3$.

Similarly, these value functions can be derived from solving Eq. (26) (31), depending on the different length of $T$, but only the three value functions are concerned about, $J^{t r}, J^{c o}$, and $J^{u}$. The same parameters as those in the last section are used and some additional settings are added ${ }^{2}$. Here in Figure 1, only the case of $T=3$ of the value function of scientists and entrepreneurs are shown since there are similar forms when $T$ equals other values. As shown in the figure, for entrepreneurs, the two value functions exist intersecting line as well. In some areas, selecting cooperation is more desirable, while in other areas, selecting one-time transfer can has larger value.

\subsubsection{Participation Constraints}

In order to make sure that the value functions being used to determine the selections and allocations in the next section can match the real world, the participation constraints should also be considered. In this model, it is also reasonable to assume that trading is better than not trading, and having inventions is better than having nothing in hand. Formally, the following expressions can be derived:

$$
\begin{gathered}
V^{i, t r}, V^{i, c o} \geq V^{i, u} \geq V^{u} \\
J^{t r}, J^{c o} \geq J^{u}
\end{gathered}
$$

These properties are used to rule out some situations in the process of simulating.

\subsection{Process of Bargaining}

To derive the final allocation of this bargaining process, the decision of the two sides is needed to be integrated together. In this model, the two sides have to first determine the form of trade, then negotiate for the allocation of the return of underlying technologies. From the aspect of each side, $V^{i, t r}$ and $V^{i, c o}, J^{t r}$ and $J^{c o}$ are compared respectively and the larger values are taken to form two new functions, which can represent the optimal selection of each side given a combination of $w$ and $c$. Then, when integrate value functions of the two sides, the two sides may be consistent in selecting the trade form in some combinations of $w$ and $c$, while in other combinations, there may exist conflicts on the optimal trade form, where some rules should be set to settle this. Here two possible rules are proposed to solve the conflict.

2 The utility function of entrepreneurs is selected as $i(w)=w^{2}, w>0$.
The first rule is based on the situation that there only exists two parties of scientists and entrepreneurs in the market, where comparison of bargaining power of the two sides completely determines the right of speech and decision in the bargaining process. Thus, it can be viewed that when one side is more powerful, the results should obey the optimal decision of that side. Comparatively, the second rule is based on the situation that there is a third party in the market, which is on the standpoint of making the integrated allocation optimal. Concretely, similar to Section 2.3, allocation can be presented in the following:

$$
(w, c)=\operatorname{argmax}_{w, c}\left\{\begin{array}{l}
\left(V^{i, t r}-V^{i, u}\right)^{\phi}\left(J^{t r}-J^{u}\right)^{1-\phi}, \\
\left(V^{i, c o}-V^{i, u}\right)^{\phi}\left(J^{c o}-J^{u}\right)^{1-\phi}
\end{array}\right\}
$$

That is, in a given combination of $w$ and $c$, results will be overall optimal based on bargaining power of the two sides.

Technology intermediaries can be viewed as the third party mentioned above. Generally speaking, technology intermediaries play the role of stimulating the willingness of technology transfer and decreasing information asymmetries. Meanwhile, technology intermediaries make profits from charging the two sides relating to the returns the underlying technologies. Therefore, when deciding the allocations, it should be on the standpoint different from the two sides to maximize its own profits. Based on this, it can be thought that its goal is to make the overall value maximized given the bargaining power of the two sides. Hossain [22] mentions that technology intermediaries have this kind of goals in the case study of five technology intermediaries in North America.

\section{Simulations}

The process of simulating is shown in the following. MATLAB is used to program, calculate and present the results.

1) Set the exogeneous variables $\theta, \alpha, \beta, N, v, M_{0}, R$ and $T$ in appropriate values, make a table that each element stands for a different combination of $w$ and $c$ ( $w$ ranges from 0 to $\lambda_{T} R$, and $c$ ranges from 0 to 1 ), then solve the equations using numerical solution and derive the corresponding value functions $V^{i, t r}, V^{i, c o}$, $V^{i, u}, V^{u}, J^{t r}, J^{c o}$ and $J^{u}$, respectively.

2) Rule out those values that do not satisfy the participation 
constraint, that is, those $V^{i, u}<V^{u}$ and the corresponding $V^{i, t r}$ and $V^{i, c o}$, those $V^{i, t r}, V^{i, c o}<$ $V^{i, u}$, and those $J^{t r}, J^{\text {co }}<J^{u}$.

3) Compare $V^{i, t r}$ with $V^{i, c o}$ of every corresponding combination of $w$ and $c$, take the larger value as the value of a new value function $V$, and record where the value comes from in another table with the same scale. Similarly, compare $J^{t r}$ with $J^{c o}$ to form a new value function $J$ and do the same thing.

4) Compare the choice of $V$ and $J$ corresponding to every combination of $w$ and $c$, respectively. If they both have the same choice, then it can be affirmed that they will certainly make this choice. If they choose different forms, then there are two kinds of rules to finally determine which one to choose. Notice that in some combinations of $w$ and $c$, one side may be only able to choose one of the trade forms because the other form of trade may contradict with the participation constraint. In this case, the other side should compromise so that the trade can be reached. Also, if

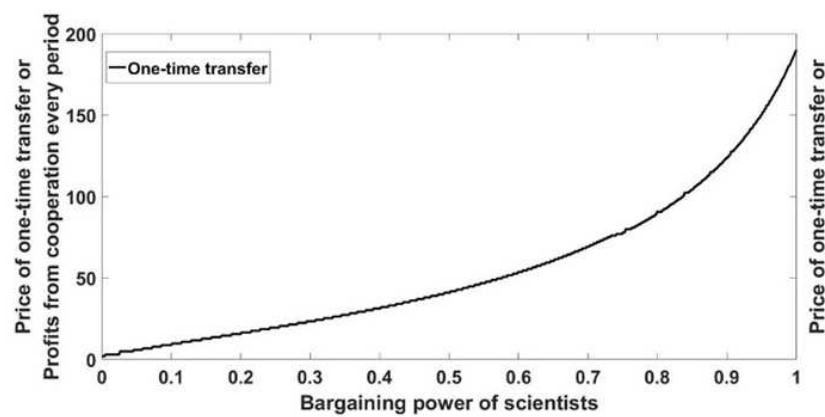

(a) $T=2$

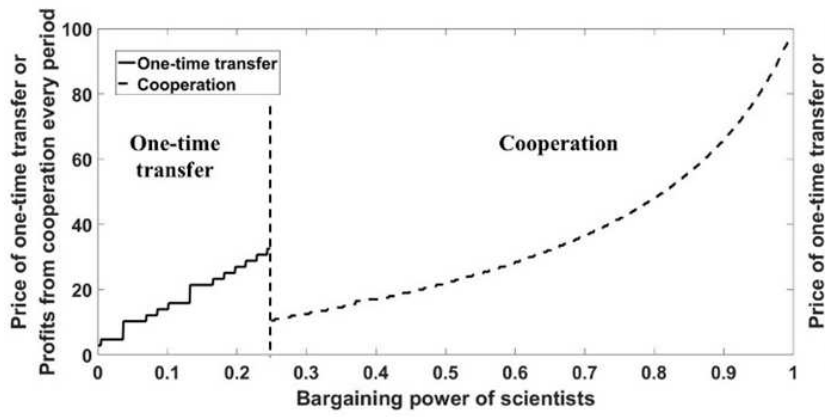

(c) $T=4$ both sides can only select one of the trade forms and their selections conflicts, the trade is impossible to be reach in this combination of $w$ and $c$, thus this kind of cases should be ruled out.

5) Set the bargaining power $\phi$ and take values ranging from 0 to 1. Rule I: For each value of $\phi$, if $\phi<0.5$, then scientists are made to compromise; if $\phi>0.5$, then entrepreneurs are made to compromise; when $\phi=0.5$, it is the same as Rule II. Rule II: For each value of $\phi$, calculate $\left(V^{i, t r}-V^{i, u}\right)^{\phi}\left(J^{t r}-J^{u}\right)^{1-\phi}$ and $\left(V^{i, c o}-V^{i, u}\right)^{\phi}\left(J^{c o}-J^{u}\right)^{1-\phi}$, respectively, then select the form of trade that has the larger value.

6) For each value of $\phi$, find out the $w$ or $c$ (depending on the selections of the corresponding element) that correspond to the largest value of $\left(V-V^{i, u}\right)^{\phi}(J-$ $\left.J^{u}\right)^{1-\phi}$, then the relationship between the bargaining power and the fees can be derived (price of one-time transfer, or returns of one period that scientists can get from the underlying technologies every period).

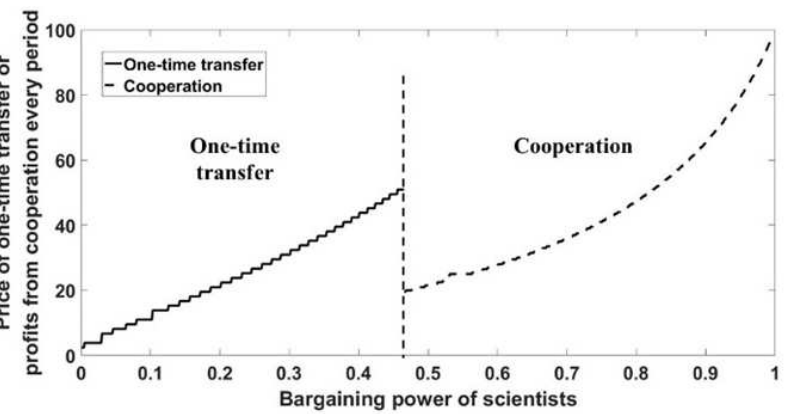

(b) $T=3$

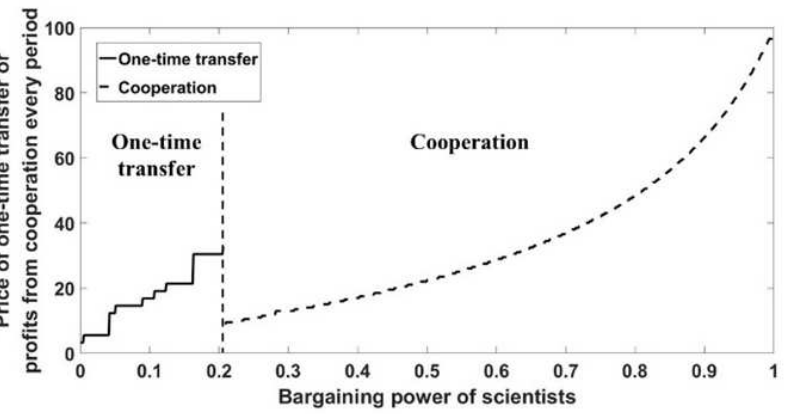

(d) $T=5$

Figure 2. Relationship between bargaining power and the fees relating to different forms of trades in different length of profitable periods.

The results are shown in Figure 2, given that the allocations of the two rules are all the same, just one of them is presented in the figure. Considering that the characteristics of the relationship will differ as $T$ differs, and the two forms of trade do not have any differences when $T=1$, only the results from $T=2$ to 5 are presented.

From the results, the following findings can be derived: First, the fee, no matter the price of one-time transfer or the proportion of returns from cooperating, increases when the bargaining power of scientists increases, which validates the conclusion in Section 2. Second, the selection will undergo a change from one-time transfer to cooperation when the bargaining power of scientists reaches a certain threshold given that $T$ is long enough, and for scientists, choosing cooperation is always desirable, while for entrepreneurs, the longer the profitable period, and the weaker their bargaining power, it is more desirable to choose cooperation. Third, while $T$ increases, the position of the threshold of changing forms of trade moves to lower bargaining power of scientists, which means cooperation will be more desirable for both parties as the profitable period become longer. Finally, the allocation of the two rules are all the same, which means introducing technology intermediaries will not influence the allocation of the two parties, and considering other merits of technology intermediaries, this provides evidences of rationality for their existences. 


\section{Discussions and Policy Implications}

Empirical studies on TT show that the incentives and driving forces that help the formation of TT relationships between scientists and entrepreneurs are complex. Researches have tried to explain this phenomenon from many different standpoints, such as the characteristics of the firms, institutes and intermediaries [23, 24], or the regional economic growth level and other geographical factors $[25,26]$. Such complexities call the need of theoretical models that can provide explanations from a more abstract and general sight.

This paper provides a matching model to describe the changing selection behavior between one-time transfer and cooperation of scientists and entrepreneurs in various situations. From the simulation results, it can be concluded that scientists and entrepreneurs have different patterns in making decisions on which form of trade they will choose when they are put in different levels of bargaining power and when the underlying technologies have different characteristics.

A first result shows that the selection of the trade form depends on the relative power between the two sides. But as long as the profitable period is long enough, compared with choosing one-time transfer, it is more desirable for the two sides to choose cooperation. In the settings of the model, the only difference between the form of one-time transfer and cooperation is that, the latter one requires that there should not have any other trades when the two sides are in the relationship of cooperation, while the former one only requires entrepreneurs to be so, and scientists can go back to their teams of research after selling the underlying technologies, and have chance to gain new ones. But according to the settings, because the probability of gaining new technologies is very low, which is always so in the real world, for scientists, they will choose staying in a relationship of cooperation to share profits from underlying technologies, rather than taking larger risks to choose one-time transfer. In addition, cooperation can exist in a more long-term goal, that is, when the profitable period becomes longer, entrepreneurs will be more willing to choose cooperation.

Moreover, two rules are presented to deal with conflicts of the selection of trade forms: one is a two-party allocation, and the other is a three-party allocation which introduction technology intermediaries as representation. From the results, the existence of technology intermediaries will not influence the allocation made purely by the two sides. However, considering in the real world, scientists are always not good at negotiating, and entrepreneurs cannot always understand the underlying technologies quite well, technology intermediaries are always needed to make the trade more smoothly. Although in some situations, scientists have to pay some fees to intermediaries and decrease their revenues, if there are difficulties when all are done by themselves, asking technology intermediaries for help is also desirable.

However, it should be realized that these may not be all the driving forces of the decision-making process, because the model is set in a situation of perfect information, which the both sides have the same level of knowledge and know the underlying technologies well enough to make decisions. In the real world, it may not always be true. Still, this model can be extended into the situations that information of both sides is asymmetrical, or that neither sides have enough knowledge to fully understand the underlying technologies and their decisions will be made through some conjectures, etc. Moreover, since the returns from the underlying technologies in the model are set to be fixed throughout periods, it can also be extended into a situation that the returns are stochastic, which will lead to other considerations on the incentives of making different decisions in different situations. All these aspects will be the problems to solve in our future researches.

\section{Appendix: Convergence of Scientists Who Are Searching in the Market}

Obviously, one-time transfer is just a special case of cooperation, if we set the probability of breaking up be one. Thus, just the case of cooperation is being investigated here. Suppose that the total number of scientists and entrepreneurs is sufficiently large, so that the number of individuals can be viewed as a continuous number. Since the number of entrepreneurs is set as a fixed number in this system, Eq. (2) can be simplified as

$$
T=M^{\prime} S^{1-\alpha}
$$

where $M^{\prime}=M_{0} v^{\alpha}$.

In Period 1 , there are $s_{1}=\theta N$ scientists who are searching in the market for cooperation, then there will be $e_{1}=T_{1}=$ $M^{\prime} s_{1}^{1-\alpha}=M^{\prime}(\theta N)^{1-\alpha}$ scientists who successfully match with entrepreneurs. In Period 2, first there are $\delta e_{1}$ scientists who break up with entrepreneurs and return to their research teams, then there are $\theta\left(\delta e_{1}+(1-\theta) N\right)+s_{1}-e_{1}$ scientists who gain technologies and search in the market. It does not matter whether $s$ is increasing or decreasing at the beginning, as long as the steady state is within the range of $N$, which will be further explained in the following.

Now suppose in Period $t$, there are $s_{t}$ scientists who are searching in the market, while there are $e_{t}$ scientists who are in the cooperating relationship with entrepreneurs, and $n_{t}$ scientists who have no technologies in hand. After the matching process of this period, the number of scientists who are in the above three states are $e_{t}+M^{\prime} s_{t}^{1-\alpha}, s_{t}-M^{\prime} s_{t}^{1-\alpha}$ and $n_{t}$, respectively. Then in Period $t+1$, the number of scientists who are searching in the market is:

$$
s_{t+1}=\left(e_{t}+M^{\prime} s_{t}^{1-\alpha}\right) \delta \theta+\left(s_{t}-M^{\prime} s_{t}^{1-\alpha}\right)+\theta n_{t}
$$

This can also be written as

$$
\dot{s}_{t}=s_{t+1}-s_{t}=M^{\prime} s_{t}^{1-\alpha}(\delta \theta-1)+\left(e_{t} \delta \theta+\theta n_{t}\right)
$$

From the above equation, the relationship between $\dot{s}_{t}$ and $s_{t}$ can roughly be presented, which is shown in Figure 3. Since

$$
\frac{\partial \dot{s}_{t}}{\partial s_{t}}=(1-\alpha)(\delta \theta-1) M^{\prime} s_{t}^{-\alpha}<0
$$


it is obvious that this function is strictly decreasing. Meanwhile, considering that in Period 2, the number of $s_{t}$ increases compare with Period 1, it can be derived that this system should start from the left side of the graph where $\dot{s}_{t}$ is above zero. If the system has a steady state, i.e., $\dot{s}=0$, the number of scientists who are searching in the market will be:

$$
\bar{S}=\left(\frac{\bar{e} \delta \theta+\theta \bar{n}}{(1-\delta \theta) M^{\prime}}\right)^{\frac{1}{1-\alpha}}
$$

where $\bar{e}$ and $\bar{n}$ are the steady state number of scientists who are in the cooperating relationship and who have nothing in hand. Note that the exact value of $\bar{e}$ and $\bar{n}$ here have not been known but they should be constant, since otherwise, $\bar{s}$ will become inconstant. When $s_{t}>\bar{s}$, which means $\dot{s}<0$, thus $s$ will decrease and move towards the steady state. When $s_{t}<\bar{s}$, which means $\dot{s}>0$, thus $s$ will increase and also move towards the steady state. In addition, the slope of the function is decreasing in absolute value, which promises the decreasing rate of change around the steady state point. Thus, it can be concluded that $s$ will finally converge to a fixed point after some periods.

Finally, it remains to show that the system can reach the steady state. If $s_{2}<s_{1}$, which means $s_{t}$ is to the right of $\bar{s}$ in Figure 3 in initial state, then from Eq. (39) we can have $\bar{s} \geq 0$, which promises that steady state is in the range of 0 to $N$ and can be reached. If $s_{2}>s_{1}$, which means $s_{t}$ is to the left of $\bar{s}$ in Figure 3 in initial state, then it can still be proved that steady state can be reached. Otherwise, from Eq. (39) and $N=\bar{s}+$ $\bar{e}+\bar{n}$ it can be known that $\bar{s} \leq N$, and if $\bar{s}$ is closed to $N$, it will make $\bar{e}$ and $\bar{n}$ converge to 0 , which will make Eq. (39) no longer be satisfied. Therefore, $\bar{s}$ is in the range of 0 to $N$ and not closed to $N$.

In all, no matter where the initial point of the system is in the range of 0 to $N, s$ will finally converge to a fixed point as periods past.

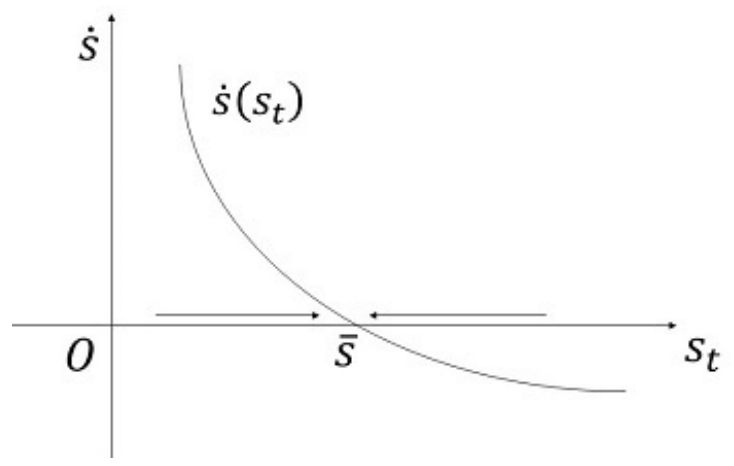

Figure 3. Changing patterns of $s_{t}$.

\section{References}

[1] Audretsch D B. From the entrepreneurial university to the university for the entrepreneurial society $[\mathrm{J}]$. The Journal of Technology Transfer, 2014, 39 (3): 313-321.

[2] Calcagnini G, Favaretto I, Giombini G, Perugini F, Rombaldoni R. The role of universities in the location of innovative start-ups [J]. The Journal of Technology Transfer, 2016, 41 (4): 670-693.

[3] Bos J W B, Candelon B, Economidou C. Does knowledge spill over across borders and technology regimes? [J]. J Prod Anal, 2016, 46 (1): 63-82.

[4] Lychagin S, Pinkse J, Slade M E, Van Reenen J. Spillovers in space: Does geography matter? [J]. J Indust Econ, 2016, 64 (2): 295-335.

[5] Roper S, Love J H, Bonner K. Firms' knowledge search and local knowledge externalities in innovation performance $[\mathrm{J}]$. Research Policy, 2017, 46 (1): 43-56.

[6] Qian H, Jung H. Solving the knowledge filter puzzle: absorptive capacity, entrepreneurship and regional development [J]. Small Bus Econ, 2017, 48 (1): 99-114.

[7] Debackere K, Veugelers R. The role of academic technology transfer organizations in improving industry science links [J]. Research Policy, 2005, 34 (3): 321-342.

[8] Calcagnini G, Giombini G, Liberati P, Travaglini G. A matching model of university-industry collaborations [J]. Small Bus Econ, 2016, 46 (1): 31-43.

[9] Banal-Estañol A, Macho-Stadler I, Pérez-Castrillo D. Research output from university-industry collaborative projects $[\mathrm{J}]$. Economic Development Quarterly, 2013, 27 (1): 71-81.

[10] Würmseher M. To each his own: Matching different entrepreneurial models to the academic scientist's individual needs [J]. Technovation, 2017, 59 1-17.

[11] Perkmann Metc. Academic engagement and commercialisation: A review of the literature on university-industry relations [J]. Research Policy, 2013, 42 (2): 423-442.

[12] Leyden D P, Link A N. Knowledge spillovers, collective entrepreneurship, and economic growth: the role of universities [J]. Small Bus Econ, 2013, 41 (4): 797-817.

[13] Lehmann E E, Menter M. University-industry collaboration and regional wealth $[\mathrm{J}]$. The Journal of Technology Transfer, 2016, 41 (6): 1284-1307.

[14] Weng H-J, Chang D-F. Determining the influence of heterogeneity in graduate institutions on university-industry collaboration policy in Taiwan [J]. Asia Pacific Education Review, 2016, 17 (3): 489-499.

[15] Link A N, Welsh D H B. From laboratory to market: on the propensity of young inventors to form a new business [J]. Small Bus Econ, 2013, 40 (1): 1-7.

[16] Pissarides C A. Search unemployment with on-the-job search [J]. The Review of Economic Studies, 1994, 61 (3): 457-475.

[17] Merz M. Search in the labor market and the real business cycle [J]. Journal of Monetary Economics, 1995, 36 (2): 269-300.

[18] Mortensen D T, Pissarides C A. Job creation and job destruction in the theory of unemployment $[\mathrm{J}]$. The Review of Economic Studies, 1994, 61 (3): 397-415.

[19] Trejos A, Wright R. Search, bargaining, money, and prices [J]. Journal of Political Economy, 1995, 103 (1): 118-141.

[20] Neal D. The complexity of job mobility among young men [J]. Journal of Labor Economics, 1999, 17 (2): 237-261. 
[21] Stiglitz J E, Weiss A. Credit rationing in markets with imperfect information [J]. The American Economic Review, 1981, 71 (3): 393-410.

[22] Hossain M. Performance and Potential of Open Innovation Intermediaries [J]. Procedia - Social and Behavioral Sciences, 2012, 58 754-764.

[23] Meoli M, Paleari S, Vismara S. Completing the technology transfer process: M\&As of science-based IPOs [J]. Small Bus Econ, 2013, 40 (2): 227-248.

[24] Huyghe A, Knockaert M, Wright M, Piva E. Technology transfer offices as boundary spanners in the pre-spin-off process: The case of a hybrid model [J]. Small Bus Econ, 2014, 43 (2): 289-307.

[25] Belderbos R A, Belderbos R A, Roy V, Duvivier F. International and domestic technology transfers and productivity growth: Firm level evidence [J]. Industrial and corporate change, 2013, 22 (1): 1-32.

[26] Dawid H, Dawid H, Zou B T. Foreign direct investment with endogenous technology choice [J]. Pacific Economic Review, 2017, 22 (1): 3-22. 